\title{
A COR ENQUANTO ELEMENTO HOMOGENEIZADOR DAS DIFERENÇAS ÉTNICAS AFRICANAS E SEUS DESDOBRAMENTOS NA ESCRAVIDÃO MODERNA E NA DESIGUALDADE SOCIAL BRASILEIRA
}

\author{
Cristina Carla Sacramento*
}

BARROS, José D’Assunção. A construção social da cor: diferença e desigualdade na formação da sociedade brasileira. Petrópolis: Vozes, 2009.

José D 'Assunção Barros é historiador e professor adjunto da Universidade Federal Rural do Rio de Janeiro. Seu livro A Construção Social da Cor, insere-se no campo de estudos da História Social, configurando-se como fruto de preocupações no que diz respeito às inter-relações dos conceitos de diferença, desigualdade e igualdade e sua utilização em mecanismos de dominação, tais como o sistema escravista.

Os primeiros trabalhos que abordam a existência de homens que deveriam servir a outros, são tão antigos quanto a própria escravidão. De acordo com Barros, é o filósofo Aristóteles quem defende a ideia de que existiriam dois tipos de escravos: os "escravos legais", que seriam aqueles homens vencidos nas guerras e os "escravos naturais" que seriam aqueles homens que teriam nascido para esse fim. Essa tentativa de definir o escravo proposta por Aristóteles na Antiguidade foi corroborada ao longo dos séculos por várias teorias que justificariam o que atualmente se conhece por escravidão moderna. Porém, o novo critério estabelecido para se escravizar um homem estava voltado para a crença de que a cor da pele seria uma marca de inferioridade. Nesse sentido, a escravidão se volta para o continente africano.

No entanto, partindo da definição aristotélica, onde o sujeito pode 'ser' escravo e/ou 'estar' escravo e ao mesmo tempo refletindo o fato de a cor se tornar critério de escravização, Barros faz alguns questionamentos, tais como:

\footnotetext{
* Mestranda no Programa de Pós-Graduação em Educação da Universidade Federal de São João del-Rei e bolsista MEC/REUNI. E-mail: criss-tina@hotmail.com
} 
“Como foi construída a noção de 'negro' (e 'branco') na sociedade brasileira? Que processos instituidores de desigualdade acompanharam a construção social destas diferenças, a começar pela introdução da escravidão de africanos no Brasil?". Tais reflexões levaram-no a desenvolver o livro em questão, aplicando os conceitos de "diferença" e "desigualdade" na história da escravidão brasileira e suas consequências.

Inicialmente, é importante destacar que, para o autor, a "diferença" está inserida no campo da essência, ou seja, é algo inerente à diversidade dos seres humanos. Ao passo que a "desigualdade" se insere no campo da circunstancialidade, podendo mesmo, passar por um processo de reversão.

Para este trabalho, realizado através de análise documental, incluindo fontes primárias, o autor aborda ao longo de vinte capítulos, desde os primórdios da escravidão até a discussão mais recente, que diz respeito às políticas de ação afirmativa. Para estabelecer relações entre os conceitos de "diferença" e "desigualdade", utilizados durante sua análise, Barros aplica a teoria semiótica proposta por Greimas \& Courtés, através da operacionalização de quadrados semióticos.

Barros se utiliza dos estudos de Finley e Cardoso, procurando distinguir a escravidão antiga da escravidão moderna, ressaltando que a escravidão antiga apresentava particularidades que se afastavam do comércio humano empreendido pelos europeus. Uma delas, por exemplo, era o fato de serem menos comerciais e mais heterogêneas no que diz respeito à origem dos sujeitos escravizados.

A escravidão moderna em particular, pode ser considerada racializada, ao contrário da escravidão antiga, uma vez que, como já foi dito, a cor da pele foi considerada um sinal de inferioridade e consequentemente, um critério para a escravidão. Importante ressaltar que os colonizadores justificavam suas ações, através do discurso bíblico, que supostamente incitaria a escravidão e teorias que dividiam a humanidade em 'raças' e atribuíam valores a cada uma. Prova disso é a referência que o autor faz a Lineu, um naturalista sueco que, no século XVIII, dividiu a humanidade em quatro 'raças' - africana, asiática, americana e europeia - e designou para a 'raça' africana características como "flegmático, astucioso, preguiçoso, negligente, governado pela vontade de seus chefes" (p. 76).

Embora a escravidão seja uma situação percebida no eixo das desigualdades, visto que as pessoas envolvidas nesse sistema podem, cedo ou tarde, recuperar a liberdade, o autor afirma que a escravidão brasileira, por vários momentos, pode ser considerada no eixo das diferenças, pelo fato de o escravo apresentar-se como um "estrangeiro absoluto", privado de qualquer direito formal e por ser, sobretudo, considerado uma "propriedade de outro". 
A análise desenvolvida por Barros permite entender que a escravidão pode ser vista como desigualdade, nos momentos em que existe a probabilidade de o escravo não mais fazer parte desse sistema, ou seja, quando ele foge para um quilombo, compra ou consegue de seu senhor a alforria. Por outro lado, nos momentos em que inexiste a condição do escravo de libertar, a escravidão pode ser entendida como uma diferença. $\mathrm{O}$ autor acrescenta ainda que, no Brasil, esse aspecto de diferença da escravidão foi expressivo, principalmente nas décadas de 1820 a 1860, quando, devido às pressões internacionais pelo fim da escravidão, os senhores não concediam a liberdade aos escravos, temendo os prováveis prejuízos ocasionados pela ausência de mão-de-obra e, ao mesmo tempo, o preço do escravo se tornou consideravelmente alto, dificultando a compra de alforrias.

Por essa razão, o autor considera que a escravidão deve ser tratada como desigualdade, ainda que radical, pois só dessa maneira, é possível pensar em propostas para sua extinção através de políticas sociais. Segundo ele, era dessa forma que os próprios escravos e os abolicionistas viam a escravidão, quando, respectivamente, fugiam para os quilombos e denunciavam o sistema nos jornais da época. Graças a atuação desses grupos que a escravidão foi deslocada do nível das diferenças para o nível das desigualdades e pôde ser combatida.

Barros aplica ainda seus conceitos na compreensão da transformação das diferentes etnias africanas à diferença negra. $\mathrm{O}$ autor explicita que, entre os séculos XVI e XIX, os africanos não se viam como "negros" em seu continente. Essa categoria de classificação, assim como o próprio continente africano, é uma construção do Ocidente Europeu. O que existia, e ainda existe no continente africano, são diferenças étnicas, manifestadas não apenas fisicamente, mas também por uma série de sinais gravados no corpo, indumentárias, tatuagens e cortes de cabelo. E à revelia dessas diferenças, o sistema escravocrata produziu "um grande continente para uma grande e única categoria de negros" (p. 42).

No Brasil, o autor aponta Nina Rodrigues como o primeiro investigador a pesquisar as origens dos africanos que formam hoje o povo brasileiro. Além dele, podem-se destacar também os estudos de Ramos e Spix \& Martius, que se ocuparam de mapear as regiões africanas que mais escravos exportaram para o Brasil.

Barros menciona também a complexidade de se tentar classificar os grupos africanos escravizados, uma vez que, apesar de pertencerem a uma etnia de origem - tais como Mbundos, Jejes, Puls - eles recebiam dos colonizadores uma classificação artificial, que seria a etnia do tráfico - Benguelas, Minas, Cabindas - e finalmente, existiria ainda a etnia da diáspora - Nagôs - criada pelos próprios negros quando chegaram ao Brasil.

$\mathrm{O}$ autor salienta que os colonos buscavam conhecer as diferenças étnicas africanas, porém, faziam isso visando sua utilidade prática, ou seja, 
pretendiam identificar quais africanos eram mais adaptáveis a determinados tipos de trabalhos a serem desempenhados na colônia. Ao mesmo tempo, empenhavam-se a agrupá-los heterogeneamente durante sua apreensão, de forma a evitar possíveis organizações e levantes. Isso implica dizer que novas identidades foram formadas a partir do tráfico negreiro, reelaboradas no Brasil a partir de manifestações culturais, como o Congado e as Irmandades. E assim, é possível identificar ao longo dos séculos, novos grupos que não estarão mais compartilhando das diferenças culturais africanas, mas que desenvolverão culturas mediadoras.

No que diz respeito aos novos grupos já nascidos no Brasil, se destacam, segundo Barros, os crioulos - negros nascidos na colônia - e os mulatos/pardos, que são os filhos de africanos com brancos europeus ou de seus descendentes. Apesar de serem ambos brasileiros, as relações entre eles nem sempre eram cordiais, pois os crioulos estariam fadados ao tratamento desigual dispensado aos escravos. Ao passo que os mulatos, por possuírem traços físicos herdados do seu genitor branco, poderiam vislumbrar mais possibilidades de ascensão social.

É nesse sentido que Barros discute o conceito de 'raça' em termos sociológicos, uma vez que, biologicamente, só faz sentido falar em 'raça' humana. $\mathrm{O}$ argumento apresentado pelo autor no sentido de apontar que 'raça' é uma construção social é o fato de que ela pode se aplicar de forma peculiar em diferentes espaços sociais. Exemplo disso é o fato de que um sujeito que, no Brasil, é considerado branco, pode ser identificado como negro em alguns estados americanos por ter um parente negro em sua ascendência.

Abolida a escravidão, Barros afirma que os ex-escravos passariam ainda da desigualdade escrava para a desigualdade liberta, ou seja, estariam sujeitos a um tratamento desigual. Isso porque nenhuma medida foi tomada para que eles fossem inseridos na sociedade e por outro lado, até as primeiras décadas do século XX ainda persistia a ideia da inferioridade negra.

Outro aspecto importante a salientar é a abordagem do autor sobre políticas afirmativas. Para ele estas podem ser consideradas um dispositivo que visa resistir à indiferença com que as minorias foram tratadas ao longo da vida, sobretudo às condições desiguais em que se desenvolveram. Para essa discussão, o autor recorre a Munanga, que defende a adoção de políticas afirmativas por acreditar que as mesmas podem dar uma resposta aos grupos discriminados, possibilitando-lhes, através de tratamento diferenciado, a compensação de desvantagens ocasionadas pela sua situação de vítimas de racismo e discriminação.

Importante destacar que o livro tem uma proposta ousada, uma vez que o recorte temporal estabelecido impossibilita, certamente, uma abordagem mais aprofundada sobre determinados conceitos ou temas, e isso é reconhecido 
pelo próprio autor. Mas ainda assim, é possível considerar que seu objetivo foi alcançado, uma vez que explorou de forma contundente questões complexas, como os desdobramentos da instituição do sistema escravista, no que diz respeito, principalmente, à influência do pertencimento étnico-racial nas posições ocupadas pelos diferentes sujeitos na sociedade.

Nesse sentido, o mérito de seu trabalho se encontra, sobretudo, na sua abordagem histórico-interpretativa, que por se estar alicerçado nas descobertas científicas, possibilita refletir sobre o deslocamento do conceito de 'raça', outrora realidade biológica, para o âmbito da sociologia. Sua abordagem sobre políticas afirmativas reafirma a necessidade de pensá-las como possibilidade não só de reparação a injustiças, mas na perspectiva de ascensão social de grupos discriminados. Sendo assim, é possível também, a partir do seu trabalho, repensar novas perspectivas em relação ao tratamento dispensado à História $\mathrm{e}$ Cultura Afro-Brasileira e ao continente africano, bem como à educação para as relações étnico-raciais.

Resenha recebida em outubro de 2011. Aceita em dezembro de 2011. 